\title{
The Response to Selection for Broad Male Response to Female Sex Pheromone and its Implications for Divergence in Close-Range Mating Behavior in the European Corn Borer Moth, Ostrinia nubilalis
}

\author{
David C. Droney $\cdot$ Callie J. Musto $\cdot$ Katie Mancuso • \\ Wendell L. Roelofs • Charles E. Linn Jr
}

Received: 29 May 2012 / Revised: 5 October 2012 / Accepted: 23 October 2012 /Published online: 6 November 2012

(C) Springer Science+Business Media New York 2012

\begin{abstract}
Coordinated sexual communication systems, seen in many species of moths, are hypothesized to be under strong stabilizing natural selection. Stabilized communication systems should be resistant to change, but there are examples of species/populations that show great diversification. A possible solution is that it is directional sexual selection on variation in male response that drives evolution. We tested a component of this model by asking whether 'rare' males (ca. $5 \%$ of all males in a population) of the European corn borer moth (ECB), Ostrinia nubilalis, that respond to the sex pheromones of both ECB and a different Ostrinia species (O. furnacalis, the Asian corn borer, $\mathrm{ACB}$ ), might play an important role in diversification. We specifically tested, via artificial selection, whether this broad male response has an evolvable genetic component. We increased the frequency of broad male response from 5 to $70 \%$ in 19 generations, showing that broad-responding males could be important for the evolution of novel communication systems in ECB. We did not find a broader range of mating acceptance of broad males by females of the base population, however, suggesting that broad response would be unlikely to increase in frequency without the involvement of other factors. However, we found that ECB selection-line females accepted a broader range of courting males, including those of ACB, than did females of the base population. Thus, a
\end{abstract}

D. C. Droney $\cdot$ K. Mancuso

Department of Biology, Hobart and William Smith Colleges, Geneva, NY 14456, USA

C. J. Musto $・$ W. L. Roelofs $\cdot$ C. E. Linn Jr $(\bowtie)$

Department of Entomology, NYS Agricultural Experiment Station,

Cornell University,

Geneva, NY 14456, USA

e-mail: CEL1@cornell.edu genetic correlation exists between broad, long-range response to female sex pheromone and the breadth of female acceptance of males at close range. These results are discussed in the context of evolution of novel communication systems in Ostrinia.

Keywords Artificial selection · Flight tunnel $\cdot$ Mating behavior - Olfaction - Sex pheromone - Sexual selection . Lepidoptera $\cdot$ Crambidae

\section{Introduction}

Explaining how coordinated mating signals and responses can simultaneously diverge into novel mating communication systems is a goal of both evolutionary and chemical ecologists (Cardé and Haynes, 2004; Coyne and Orr, 2004; Smadja and Butlin, 2009; Symonds and Elgar, 2008). Intuitively, the need for coordination between males and females should disfavor changes in a mating signal without a simultaneous change in response. The low probability of simultaneous changes in independently controlled traits has supported the idea of 'Specific Mate Recognition Systems' (SMRS; Paterson, 1985). Despite this reasoning, rapid diversification of animal mating communication systems has occurred in several taxa, running counter to the concept of the SMRS and the role of stabilizing selection in maintaining a coordinated communication system (Phelan, 1992, 1997a, b). How this occurs is still largely unknown, but research has shifted from a focus on divergence as an indirect by-product of natural selection on other traits to the direct action of sexual selection on mating communication systems (Andersson, 1994; Panhuis et al., 2001). 
A striking example of rapid change in mating signals/ responses is seen in the sex pheromones of two moth species in the genus Ostrinia (Lepidoptera: Crambidae), the European (ECB) and Asian (ACB) corn borer moths (Ostrinia nubilalis and $O$. furnacalis, respectively). In a study of the sex pheromones of seven Ostrinia species in Japan, Ishikawa et al. (1999) showed that they all use mixtures of (Z)- and (E)-11tetradecenyl acetates (Z/E11-14:OAcs), derived from a biosynthetic pathway utilizing a $\Delta 11$-desaturase, except for the ACB, which uses a mixture of $(Z)$ - and $(E)$-12-tetradecenyl acetates (Z/E12-14:OAc), produced via a $\Delta 14$-desaturase (Ando et al., 1980). It was proposed that ACB is derived from one of the closely related Ostrinia populations that uses $\Delta 11$ components, one very similar to ECB (Roelofs et al., 2002). Characterization of the $\Delta 11$ - and $\Delta 14$-desaturase genes, found in the pheromone glands of females of both $\mathrm{ACB}$ and $\mathrm{ECB}$, suggested that recruitment of the $\triangle 14$ enzyme by ACB resulted in the establishment of a novel pheromone blend that ultimately led to the divergence of this species from an ECB-like ancestor (Roelofs and Rooney, 2003; Xue et al., 2007). Proof that differential suppression of the two genes was occurring came from another study, using ACB and O. scapulalis, the Adzuki bean borer (Sakai et al., 2009). Although both species have both $\Delta 11$ - and $\Delta 14$-desaturase genes, transcription from the $\Delta 14$-desaturase gene was strongly suppressed in $O$. scapulalis, as was transcription from the $\Delta 11$-desaturase gene in ACB. Based on these findings, the authors discussed the evolution of sex pheromone biosynthesis in O. scapulalis and ACB.

The observation that a change in mate communication systems can occur by a change in the female-produced blend raises the question of how such a female will attract males to mate with (Baker, 2002)? One path to resolving this paradox in Lepidoptera has been suggested by Phelan (1992, 1997a, b), who proposed a sexual selection model called the Asymmetric Tracking Hypothesis (ATH). The ATH proposes that within populations greater variation will exist in male response to female sex pheromone than in the female pheromone. Mutations producing divergent female pheromone might then still be 'tracked' by some variant males within the population. Because only some males detect this new signal, assortative mating between these males and 'mutant' females could occur and result in a novel mating system. Although the ATH is often discussed in terms of quantitative variation in pheromone blends, the central component of the hypothesis also applies to qualitative variations in pheromone.

Despite the conceptual contribution of the ATH to focusing on sexual selection, several issues surround the model. First, it is unclear how the proposed new signal/receiver communication system could evolve to fixation without some evolutionary force favoring the increase in new communication traits (Baker, 2002). Second, in many moth species, the mating communication system involves two distinct levels of signal and response; male detection of long-range (mate location) sex pheromones released by females, and close-range courtship (mate choice) pheromones released by males (Phelan and Baker, 1987; Baker, 1989; Krasnoff and Roelofs, 1990; Phelan, 1992; Hillier and Vickers, 2004; Lassance and Löfstedt, 2009). The ATH is discussed only in the context of long-range mate location signals, but sexual selection theory has been developed mostly with regard to close-range mating traits, raising questions on how the ATH might apply to mating system divergence in moths, such as Ostrinia species. Also, considering divergence in mating traits at only one spatial scale might be misleading, because male long-range response and the close-range courtship signal should be integrated to some degree and, thus, changes at one scale could produce unexpected changes at the other (Lassance and Löfstedt, 2009).

A number of studies have shown that males have varying 'breadth of response', supporting the ATH, but this standing variation has not typically included response to pheromones of other species (Haynes et al., 1984; Glover et al., 1987, 1991; Löfstedt, 1990, 1993; Linn and Roelofs, 1995; Haynes, 1997; Linn et al., 1997 Allison and Cardé, 2008). The recent discovery in ECB and ACB of a small number (3-5\%) of 'rare' or 'broad response' males that can detect and respond behaviorally to the sex pheromone of a different species, as well as to the signal of their own females, has obvious relevance to the ATH and sexual selectiondivergence models in general (Roelofs et al., 2002; Linn et al., 2003, 2007). Unfortunately, little is known about the biology of broad response in Ostrinia, including the extent to which it is genetically controlled and can evolve via selection. Also, the relationship between variation in longrange male response to sex pheromone and variation in courtship signals (and mating success) has not been studied in ECB. Here, we addressed these questions by determining whether the naturally occurring low frequency of rare ECB males that respond to both $\mathrm{ECB}$ and $\mathrm{ACB}$ female sex pheromones can be increased through artificial selection. We also investigated whether there is a genetic correlation between long-range response and close-range mating signals of males. We tested specifically whether broad response ECB males, which fly upwind to both ECB and ACB sex pheromones, have higher mating success with $\mathrm{ACB}$ females than do narrow response ECB colony males, which is required for broadly tracking males to be an important component of communication system divergence.

\section{Methods and Materials}

Insects Experimental animals were obtained from our ECB Z-strain colony, which was initiated from individuals (about 200) collected in 1994 from several sites in the vicinity of Geneva, NY, USA. The ACB colony originated from Jin 
Kyo Jung, National Institute of Crop Sciences, South Korea. Laboratory rearing conditions for $\mathrm{ECB}$ and $\mathrm{ACB}$ are described in detail in Roelofs et al. (1987) and Linn et al. (2007). Insects were sexed as pupae, and placed on a layer of vermiculite in single-sex emergence cages. Cages were kept in a walk-in environmental chamber set at $25^{\circ} \mathrm{C}$, 16:8 L:D, and $\mathrm{RH}=40-50 \%$. Emergence cages were changed daily so that males of known age could be tested in the flight tunnel.

Flight Tunnel Males were tested in a sustained-flight tunnel during their 2 nd to 3 rd night as adults, under standardized conditions for $O$. nubilalis (Glover et al., 1987; Linn et al., 1997, 2003): $20-21{ }^{\circ} \mathrm{C}, 60-65 \% \mathrm{RH}, 0.50 \mathrm{~cm} / \mathrm{s}$ air flow, and 11 lux of red light at the tunnel floor, during hours 3-6 of the scotophase. Adult males of known age were taken to the room housing the flight tunnel, $1 \mathrm{~h}$ prior to the start of scotophase, and placed individually in mesh screen release cages, so they could acclimate during the last hour of photophase at $25^{\circ} \mathrm{C}$ and $1200 \mathrm{~lx}$ fluorescent white-light illumination levels. When scotophase began, illumination was reduced to $11 \mathrm{~lx}$ of red incandescent light, and the temperature reduced to $20-21{ }^{\circ} \mathrm{C}$. Adult males were tested individually, and a positive response was scored if a male oriented in the pheromone plume in an upwind heading and then exhibited upwind directed flight to a point 25 , 50,75 , or $100 \%$ (source contact) of the initial distance $(1.5 \mathrm{~m})$ to the source. Each male was tested to both Z-race (30 $\mu \mathrm{g}$ dose of 97:3 Z/E11-14:OAc) and ACB (100 $\mu \mathrm{g}$ 2:1 $\mathrm{Z} / \mathrm{E} 12-14: \mathrm{OAc}$ ) blends within a 4-h period [ECB males can be tested up to 4 times in one $2-4 \mathrm{~h}$ test period without an apparent change in their response (Cossé et al., 1995)]. Order of testing was randomized across males. The blends were prepared in HPLC-grade hexane and applied to red rubber septa (hexane soaked; Thomas Scientific, Swedesboro, NJ, USA, Cat. no. 1780 J07).

Selection Protocol We evaluated whether male broad response has a genetic basis that could be increased in frequency in our ECB Z colony, by artificially selecting for males that detect and initiate flight to both $\mathrm{ECB} Z$ and $\mathrm{ACB}$ pheromone blends. Because broad response is dichotomous in nature (i.e., a threshold character), male-limited and initially rare (3-5\% of the population), we used a familyselection protocol, which is a more efficient design than individual selection under these conditions (Falconer and Mackay, 1996). Thirty broad response males that completed flights to, and landed on, the ACB lure were identified in the ECB Z colony through flight-tunnel tests (from observations of $>600$ arbitrarily chosen males), and then mated singly to arbitrarily chosen colony females, so as to produce families for selection of the broad-response phenotype; twenty-one of these crosses produced adequate progeny numbers for further study and comprised our initial selection lines (families). We chose 20 males per family line and tested them in the flight tunnel to obtain the proportion of broad responders per family. We tested 20 males/family x 21 families, resulting in 420 males flown in the tunnel per round of selection. Following procedures for family selection on threshold traits, we chose males as sires for the next generation from families with the highest proportion of broad-responding males. Three males from each of the 7 top-ranking families, and 3 females from each of the next 7 top-ranking families (i.e., families ranked $8-14$, based on proportion of broad-response males), were kept as parents each generation. Females were not collected from the 7 topranking families, because this would have resulted in several brother-sister pairings and possibly would have introduced confounding effects of strong inbreeding. Although family selection is based only on the family proportion of broad response, and not on individual male phenotype, we chose males that had a broad response, if possible. When not enough broad response males were found in a family, we arbitrarily selected a narrow response male from the chosen family. Females were chosen as future parents, based on the mean proportion of brothers that showed broad response (i.e., sib selection, Falconer and MacKay, 1996), because females do not exhibit long-range responses. We used a round-robin mating procedure to pair males and females to produce the next generation of 21 families. For example, we paired 1 of the 3 males from the highest-ranking family with a female from the $8^{\text {th }}$-ranked family, another with a female from the $9^{\text {th }}$-ranked family, and the 3 rd male was paired with a female from the $10^{\text {th }}$-ranked family, etc. Thus, 7 of 21 families were dropped each generation, based on family proportions of broad-responding males, resulting in a mild selection differential per generation. A control population of unselected ECB colony individuals was maintained under similar conditions.

All matings occurred in $15 \times 12 \mathrm{~cm}$ cylindrical screen cages, provided with water, with the tops of the cages covered with wax paper as an oviposition substrate. Pairs were left for 2-3 nights before larvae were collected for development on artificial media (Roelofs et al., 1987). A complete replication of the selection procedure was not feasible, due to the labor-intensive nature of our design, nor was down selection practical, given the low starting frequencies in the colony of broad response males. Selection was relaxed from generations 10 through 15 and then resumed, as before, at generation 16. During the period of no selection, individuals were kept in large mixed-sex enclosures and allowed to mate freely.

Mating Experiments Two different mating experiments were performed. To evaluate whether ECB and ACB have also diverged in close-range courtship signals and mating 
preferences, we paired virgin ECB colony and ACB adults and recorded whether copulation occurred. In a separate experiment, we tested whether selection on male longrange response altered close-range male courtship and female preferences, by pairing ECB selection line with ECBcolony or ACB individuals. For each experiment, we tested the null hypothesis that the frequencies of 'mating' and 'not mating' fit the expected random distribution using the general loglinear procedure of SPSS 19.

Virgin males and females (age $=4 \mathrm{~d}$ ) were collected from single-sex holding cages at the beginning of scotophase and placed in pairs in clear plastic $(10 \times 10 \times 10 \mathrm{~cm})$ boxes. Boxes were fitted with a lid, covered with wax paper that allowed moths to court and mate on the underside of the lid. We placed cotton, saturated with water, into each enclosure to maintain high relative humidity. We observed moths for matings over the last $6 \mathrm{~h}$ of scotophase; preliminary observations of moths throughout scotophase revealed that copulations usually occurred within the last $4 \mathrm{~h}$, and most within the last $2 \mathrm{~h}$ of scotophase. We observed enclosures directly for copulations, but a subset was also videotaped from the time a male and female were introduced into the enclosure, so that we could examine details of precopulatory mating behavior. Duration of copulation was recorded, because mate preferences might also be manifest in aborted copulations. We observed 12 boxes simultaneously by arranging them on the floor of a flight tunnel under low light conditions. We regularly scanned all boxes and recorded any matings that occurred. Because ECB and ACB matings usually last about $2 \mathrm{~h}$ (unpublished data), it is unlikely any were missed. At the conclusion of copulation, males were removed but females allowed to remain in the box for $2 \mathrm{~d}$ longer to allow oviposition. Eggs were counted and kept for another $4 \mathrm{~d}$, when they were examined for the presence of larval head capsules; survival to the head capsule stage was our index of a fertile mating. We tested for differences among mating combinations in offspring production to determine whether there are possible fitness consequences to inter-specific matings compared to conspecific (including ECB selection- and colony populations) matings. Number of larvae was square root-transformed prior to analysis using the GLM procedure of SPSS 19.

\section{Results}

The frequency of broad-responding males increased during 19 generations of artificial selection from an initial value of $4.6 \%$ (30 broad responders $/ 640$ males tested) to $70 \%$ (Fig. 1). The initial frequency of broad response in our selection experiment is consistent with values obtained for this colony over many years of testing, and also with the unselected control line at the end of our experiment ( $5 \%$ ). Although we selected only on the ability of a Z-strain male to detect and initiate upwind-directed flight toward both ACB- and ECB-Z-pheromone blends, the proportion of completed flights to the pheromone source also increased over generations (Fig. 2). Thus, selection for males that detected and oriented in the pheromone plume of a related species also had the effect of increasing the completeness of the response. Also, note that all Z-race males that responded to the ACB blend also responded to their own Z-race lure.

Allowing selection-line individuals to choose their mates (i.e., relaxing selection) during generations $10-15$ resulted in a consistent decline in the frequencies of overall and completed broad response toward baseline levels (Figs. 1 and 2). Resumption of selection in generation 17 led to a sharp jump in the frequency of broad response.

Matings occurred readily during the one-day period of the mating experiments (Tables 1 and 2). The likelihood of mating was not random among the pairings of ECB-colony and ACB individuals (overall goodness of fit: $G_{3}^{2}=26.5, P<0.001$; Table 1). Analysis of the pattern of the deviance residuals reveals that mating was more likely to occur in the ECB colony $x$ ECB colony pairings and less likely with the ECB colony $\mathrm{x}$ ACB combination (Table 1), as expected if ECB and $\mathrm{ACB}$ have also diverged in close-range mating signals.

The pattern of mating success across pairings involving ECB selection-line individuals was also not random (overall goodness-of-fit, $G_{3}{ }_{3}=36.2, P<0.001$; Table 2). The deviance residuals for each mating combination indicated that there were more matings than expected in both ECB selection line $\mathrm{x}$ colony pairings and fewer matings than expected in the $\mathrm{ECB}$ selection-line male $\mathrm{x}$ ACB female pairing. However, the ECB selection-line female $\mathrm{x}$ ACB male combination did not deviate from random expectation (i.e., equal number of matings across cells), which means that ECB selection-line females discriminated less against $\mathrm{ACB}$ males than did ECB-colony females. In fact, ECB selection-line females were more likely to accept ACB males as mates than were ECB-colony males (data re-analyzed from Tables 1 and 2; alpha was reduced to 0.025 to protect against Type I error due to multiple comparisons). Specifically, ECB-colony females mated ACB males in 3 of 20 observations, whereas ECB 'selection-line' females accepted ACB males in 14 of 25 observations (test of equal probability of mating: $X^{2}=7.95, P=0.012$ ).

Behavioral observations showed that females cannot be forced to copulate, and that they often rejected males by either moving away or lifting their abdomens away from the substrate. No females mated more than once during the 1-d observation period. Duration of copulation did not vary among mating combinations (ANOVA: $F_{7,77}=0.536$, NS), which suggests that females did not exercise mating preferences after initiation of copulation by disengaging earlier from heterospecific males, for example. The number of 
Fig. 1 The proportions of European corn borer (ECB) males that exhibited upwind oriented flight to both ECB and Asian corn borer (ACB) female sex pheromones over 19 generations of selection

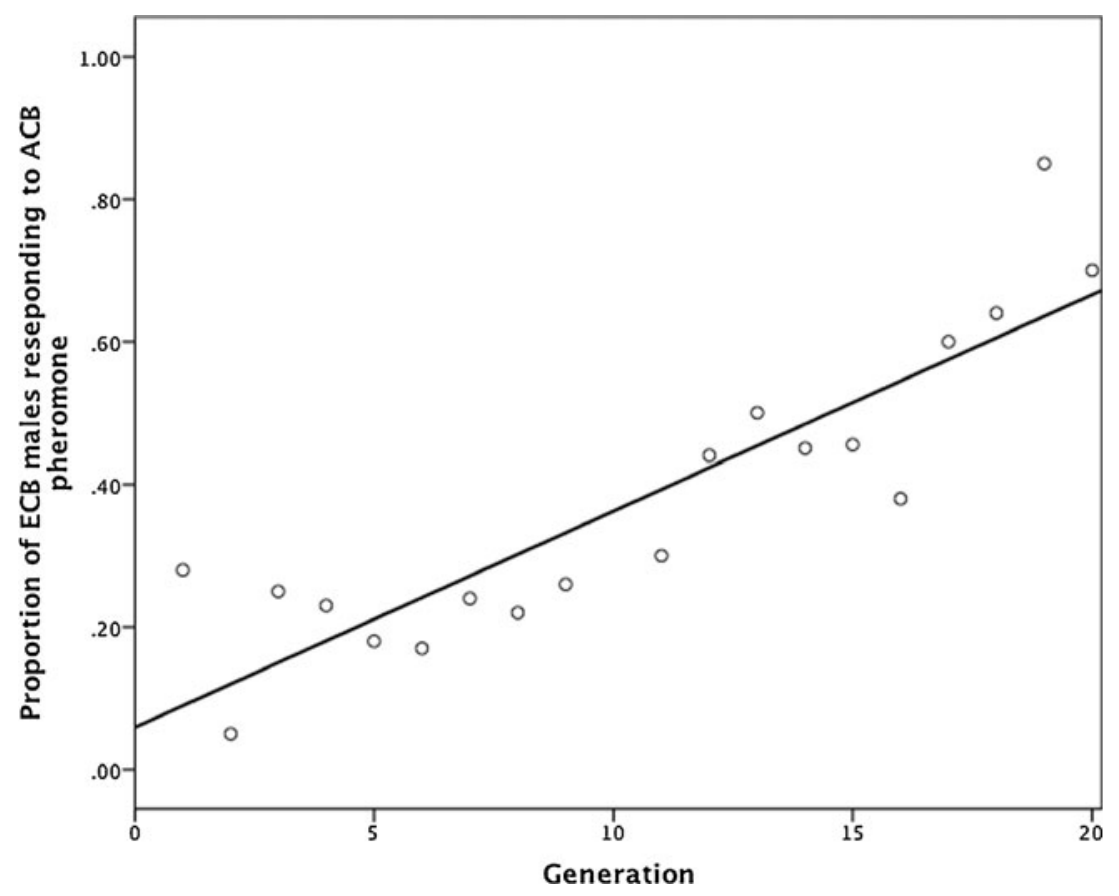

offspring produced (number of eggs with head capsules) did not differ among mating combinations (ANOVA: $\left.F_{6,117}=1.681, P=0.132\right)$.

\section{Discussion}

The increase, via artificial selection, in the frequency of ECB males that can respond broadly to both ECB and

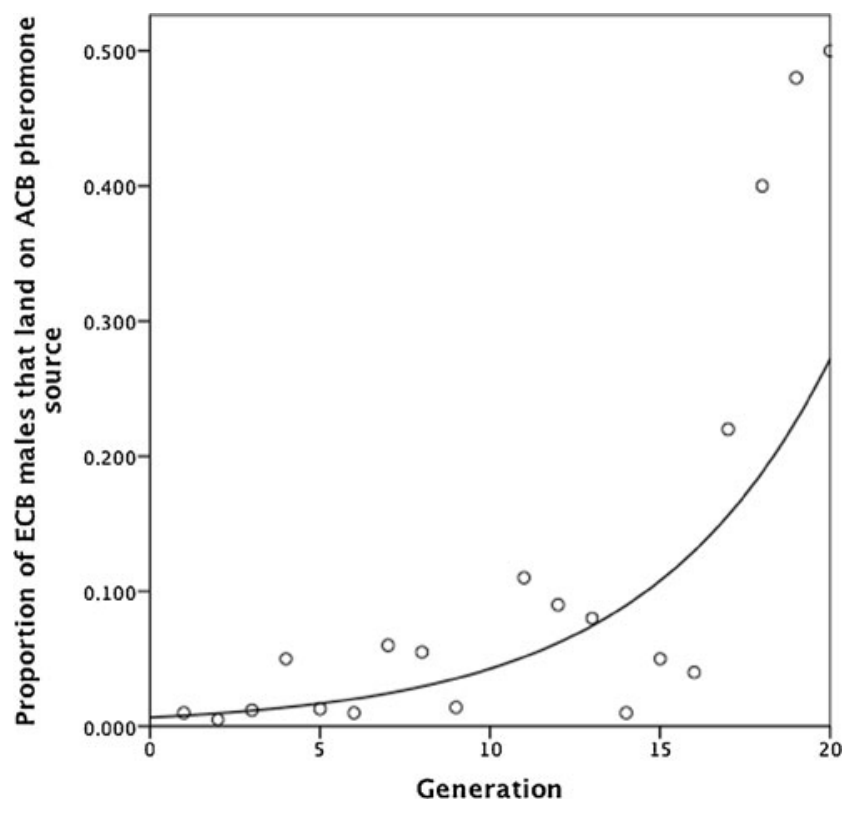

Fig. 2 The proportions of European corn borer (ECB) males that flew upwind in the flight tunnel and landed on the Asian corn borer (ACB) female sex pheromone source over 19 generations of selection
ACB sex pheromones demonstrated that broad response has an evolvable genetic basis in our ECB Z colony. Logistics prevented us from fully replicating the selection experiment, precluding reliable estimates of genetic parameters (e.g., heritability of broad response) (Hill and Caballero, 1992; Falconer and MacKay, 1996; Kearsey and Pooni, 1996). However, relaxation of selection after generation 9 , followed by resumption in generation 15 , provided a partial replication of the selection experiment. During this period of no selection, the frequency of broad

Table 1 The number of copulations and 'no copulations' occurring during a one-day 'no choice' mating experiment involving pairs of individuals from European corn borer (ECB) colony and/or Asian corn borer (ACB) populations

\begin{tabular}{llll}
\hline $\begin{array}{l}\text { Mating combination } \\
\text { female x male) }\end{array}$ & $\begin{array}{l}\text { Number } \\
\text { mating }\end{array}$ & $\begin{array}{l}\text { Number not } \\
\text { mating }\end{array}$ & $\begin{array}{l}\text { Total } \\
\text { observations }\end{array}$ \\
\hline ECB colony x ECB colony & 37 & 20 & 57 \\
& $(27.9)$ & $(29.0)$ & \\
ACB x ECB colony & $\mathbf{6}$ & $\mathbf{2 3}$ & 29 \\
ECB colony x ACB & $\mathbf{( 1 4 . 2 ) *}$ & $\mathbf{( 1 4 . 8 )}$ & \\
ACB x ACB & $\mathbf{3}$ & $\mathbf{1 7}$ & 20 \\
& $\mathbf{( 9 . 2 )}$ & $\mathbf{( 1 0 . 8 )}$ & \\
& 15 & 11 & 26 \\
& $(12.0)$ & $(14.0)$ &
\end{tabular}

Overall fit of the null model: $G^{2}{ }_{3}=26.5, P<0.001$

*Boldface type indicates cells that contribute significantly to the overall lack of fit of the null model, based on analysis of the deviance residuals; numbers in parentheses are the expected numbers in each cell based on the null model of an equal likelihood of mating across cells 
Table 2 The number of observations that resulted in mating or not mating in a 'no choice' mating experiment involving a 'selection line' individual (see text) paired with either an Asian corn borer (ACB) or European corn borer (ECB)individual

\begin{tabular}{|c|c|c|c|}
\hline $\begin{array}{l}\text { Mating combination } \\
\text { (female } \mathrm{x} \text { male) }\end{array}$ & $\begin{array}{l}\text { Number } \\
\text { mating }\end{array}$ & $\begin{array}{l}\text { Number not } \\
\text { mating }\end{array}$ & $\begin{array}{l}\text { Total } \\
\text { observations }\end{array}$ \\
\hline $\begin{array}{l}\text { ECB colony x ECB } \\
\text { 'selection line' }\end{array}$ & $\begin{array}{l}32 \\
(24.5)^{*}\end{array}$ & $\begin{array}{l}13 \\
(20.5)\end{array}$ & 45 \\
\hline $\begin{array}{l}\text { ECB 'selection line' } \\
\text { x ECB colony }\end{array}$ & $\begin{array}{l}36 \\
(26.6)\end{array}$ & $\begin{array}{l}13 \\
(22.4)\end{array}$ & 49 \\
\hline $\begin{array}{l}\text { ECB 'selection line' } \\
\text { x ACB }\end{array}$ & $\begin{array}{l}14 \\
(13.6)\end{array}$ & $\begin{array}{l}11 \\
(11.4)\end{array}$ & 25 \\
\hline $\begin{array}{l}\text { ACB x ECB } \\
\text { 'selection line' }\end{array}$ & $\begin{array}{l}12 \\
(29.3)\end{array}$ & $\begin{array}{l}42 \\
(24.7)\end{array}$ & 54 \\
\hline
\end{tabular}

Overall fit of the null model: $G^{2}{ }_{3}=36.2, P<0.001$

* Numbers in parentheses represent the expected number of 'mating' and 'not mating' outcomes according to the null hypothesis of equal likelihood of mating among cells; Boldface type indicates statistically significant $(P<0.05)$ differences between observed and expected values based on deviance residuals

response decreased consistently. When selection was resumed, frequency of broad response increased in a manner similar to earlier generations of selection. Although many factors probably varied between the selection and relaxed periods, one difference was that females could choose among many males over a longer time during the relaxed selection period, but could not choose among males during the one-day selection period. The opportunity to choose among several males might have resulted in female discrimination against broad response males and caused the decline in the frequency of these males in subsequent generations prior to the resumption of selection.

Although our study was not designed to investigate the genetic architecture underlying broad response, two of our results suggest that it is likely controlled by several loci and appears to be a quantitative trait (Lynch and Walsh, 1998). First, the gradual increase in response to selection, followed by gradual decrease in the absence of selection, is typical of quantitative traits. In fact, the selection protocol we employed is commonly used for quantitative threshold traits in which it is assumed that response (presence of trait) occurs when the contributions to the phenotype from several different loci finally exceed some threshold and the phenotype is observed (Falconer and Mackay, 1996). Our selection protocol involved using as sires many males who did not possess broad response, but were from a family with a relatively high proportion of brothers who did, suggesting a quantitative threshold trait.

Second, in addition to the increase in general broad response (i.e., at minimum, initiating upwind flight to female sex pheromone), we also observed a consistent increase over generations in the proportion of completed upwind flights to the pheromone source. The fact that the nature of broad response also changed over 19 generations of selection (i.e., completed flights increased) suggests that several different loci are involved in broad response regarding detection, orientation and flight to a female. Completed flights are the critical metric in nature, of course, because males must land near females and then court at close range to achieve copulation. Imprecise or delayed arrival at a female would be disadvantageous in nature when males are in competition with narrow-response males. This fact may help explain the low frequencies of broad response in nature. Our interpretation of polygenic control is consistent with results of several genetic studies on long-range sex pheromones in ECB and other species, which have shown that several loci are involved in production/response (Löfstedt, 1993; Haynes, 1997; Cardé and Haynes, 2004; Domingue et al., 2006; Allison and Cardé, 2007, 2008; Pélezuelo et al. 2007; Symonds and Elgar, 2008; Lassance and Löfstedt, 2009; Smadja and Butlin, 2009; Lassance, 2010).

A number of other studies have used selection protocols to examine for the potential to change pheromone production and/or male response specificity. Three studies, using the redbanded leafroller, Argyrotaenia velutinana (Sreng et al., 1989), the pink bollworm, Pectinophora gossypiella (Collins and Cardé, 1989), and the almond moth, Cadra Cautellla (Allison and Cardé, 2007), showed that changes could be produced in pheromone component ratios in high and low selection lines, but the changes did not result in blends that were significantly outside the response profiles for males. However, in a fourth study, on geographical variation in pheromone blend composition in the cabbage looper moth, Trichoplusia ni, Haynes and Hunt (1990) isolated a single female that produced an abnormal pheromone phenotype, outside the range produced by normal females. After 49 generations, the response of males was high to both the mutant blend and the normal blend (Haynes, 1997), a result similar to that observed here with Z-race ECB. Moreover, these results are consistent with components of the ATH, which requires that some males in a predominantly narrow-response population possess broad responses that can track novel mutations in female sex pheromone (Phelan, 1992, 1997a, b).

The increase of broad, long-range response to positive selection suggests that this trait might be critical in the evolution of sexual communication system divergence between and within Ostrinia species. In a previous study with ECB and ACB, Domingue et al. (2007) showed that normal $\mathrm{ACB}$ males are not responsive to the ECB blends, because they express an antennal sensory response to Z11-14:OAc, the major component of the ECB pheromone, on the antagonist neuron that normally responds to Z9-14:OAc. This 'antagonist imposition' was hypothesized to be one step in 
the process of assortative mating effecting isolation in populations that were producing and responding to mixtures of the ECB and ACB components, such as individuals in our selection lines.

Long-range mate location is a critical aspect of mating behavior in ECB and ACB. However, after locating a female, males must display appropriate courtship signals that satisfy the mating criteria of females (Pélezuelo et al. 2007; Lassance and Löfstedt, 2009). In ECB, males release courtship pheromones, produced in hair pencil glands, which are used by females to discriminate age and possibly population/species origin of courting males (Lassance and Löfstedt, 2009). Female choice, based on closerange signals, suggests that a genetic correlation might evolve between a male's long-range response phenotype and the pheromone profile of his courtship signals. Specifically, we expect that broad, long-range response phenotypes should be coupled with a broader courtship pheromone profile that satisfies a greater variety of females, at least when considering different species, such as ECB and ACB. Within populations, this expectation might not hold if changes in female sex pheromone are independent of male courtship pheromones; in this case, females would essentially be unchanged in their choice criteria relative to females with population 'typical' sex pheromones and would readily mate with broad-responding males that court them. Results from our mating experiments are pertinent to both of these issues. We failed to find evidence for a correlation between male broad, long-range response and mating success with novel females (ECB males $\mathrm{x}$ ACB females), as broad-response males were no more likely to be accepted by ACB females than were narrow-response males from the base colony (seen by comparing results presented in Tables 1 and 2). Apparently, there is no significant coupling between long-range response of males and their close-range courtship signal profiles (Allison et al., 2008). Broad response males would expend considerable time and energy locating and courting ACB females with little likelihood of actually mating. In general, broad response might be costly for males because of the potential for wasting time and energy flying to females of the 'wrong' species. Moreover, broad response might be negatively correlated to sensitivity to the population-typical pheromone, as was demonstrated with $T$. ni (e.g., Hemmann et al., 2008)

A genetic correlation appears to exist, however, between broad response of males and female mating behavior. Our selection protocol involved 19 generations of direct selection on males for response to both ECB and ACB sex pheromones, with females not under any direct selection. After 19 generations, however, females from the selection line had a broader acceptance range of males as mates. Selection-line females were more likely to accept a courting ACB male than were ECB females from the base colony.
Apparently, direct selection for broad long-range response caused a broadening of female mating acceptance criteria as a correlated response to selection.

This interpretation is consistent with recent work on ECB communication systems. Lassance and Löfstedt (2009) found that female sex, and male courtship, pheromones are derived from a common pool of precursors and, therefore, likely controlled by many of the same genes (i.e., are genetically correlated). Selection for changes in one trait should cause correlated changes in the other trait. Pélezuelo et al. (2007) conducted mating experiments involving ECB Z and E populations, and found that females discriminated among males based on close-range signals. Mate acceptance was not correlated to sex pheromone population (E or Z) but, rather, on the genetic backgrounds of females and males, regardless of sex pheromone population. That mating depended on the genetic backgrounds of males and females in the Pélezuelo et al. (2007) study is consistent with coevolution (via a genetic correlation) of male signals and female signal preferences. Correlations between male longrange responses and close-range signals and mating success were not considered.

Collectively, studies of ECB show that both long- and close-range signals are involved in reducing gene flow between established populations, and could also be involved in the early stages of the evolution of reproductive barriers. Although we found that ECB and ACB are isolated by close-range courtship signals via female choice, we also observed that ACB and ECB did hybridize. Also, viable offspring were produced and ACB x ECB matings did not result in fewer or obviously less viable larvae being produced. Copulations with intra- and inter-specific individuals also did not differ in duration.

In general, reproductive barriers arising from long-range and close-range signal differences are important in ECB but each, individually, appears relatively easy to cross. However, intra-sexual selection on long-range response, in conjunction with inter-sexual selection for close-range male courtship signals, as must occur in ECB, might together be highly reinforcing and lead to strong and quick isolation between diverging populations, maintaining differences between recently diverged populations. Whether divergence occurs might depend on baseline frequencies of both breadth of female mate acceptance and breadth of long-range response that exists in a population. In this regard, the ATH is not sufficiently complex to explain communication system divergence if two levels of sexual selection are acting on two different, but correlated, traits essential for mating in ECB.

Acknowledgments We thank Kathy Poole and Paula Fox for help in maintaining the moth colonies and selection lines. We also thank Tom Glover for discussion on the selection protocol. The research was supported by a grant to W.L.R and C.E.L from the National Science Foundation \#0343409. 


\section{References}

Allison, J. D. and CARDÉ, R. T. 2007. Bidirectional selection for novel pheromone blend ratios in the almond moth, Cadra cautella. J. Chem. Ecol. 33:2293-2307.

Allison, J. D. and CARDÉ, R. T. 2008. Male pheromone blend preference function measured in choice and no-choice wind tunnel trials with almond moths. Cadra cautella. Animal Behaviour. 76:259-266.

Allison, J. D., RofF, D. A., and CARdÉ, R. T. 2008. Genetic independence of female signal form and male receiver design in the almond moth, Cadra cautella. J. Evol. Biol. 21:1666-1672.

ANDERSSON, M. 1994. Sexual Selection. Princeton Univ. Press.

ANDO, T., SAITO, O., ARAI, K., AND TAKAHASHI, N. 1980. $(Z)$ and $(E)$ 12-Tetradecenyl; acetates: Sex pheromone components of oriental corn borer (Lepidoptera: Pyralidae. Agri. Biol. Chem. 44:26432649.

BAKER, T. C. 1989. Origin of courtship and sex pheromones of the oriental fruit moth and a discussion of the role of phytochemicals in the evolution of Lepidopteran male scents. pp 401-418, in C. H. Chou, and G. R. Walker, (eds.). Phytochemical Ecology: Alleochemicals, Mycotoxins, and insect pheromones and allomones, Monograph series No. 9, Institute of Botany, Academica Sinica, Taipei.

BAKER, T. C. 2002. Mechanism for saltational shifts in pheromone communication systems. Proc. Natl. Acad. Sci. USA 99: 13368-13370.

CARDÉ, R. T. and HAYNES, K. F. 2004. Structure of the pheromone communication channel in moths, pp. 283-332, in R. T. Cardé and J. G. Millar (eds.), Advances in Insect Chemical Ecology. Cambridge University Press, Cambridge, UK.

COLlins, R. D. and CARDÉ, R. T. 1989. Selection for altered pheromone-component ratios in the pink bollworm moth, Pectinophora gossypiella (Lepidoptera: Gelechiidae). J. Insect Behav. 2:609-621.

Cossé, A. A., Campbell, M. G., Glover, T. J., Linn JR., C. E., TODD, J. L., BAKER, T. C., and RoElofS, W. L. 1995. Pheromone behavioral response in unusual male European corn borer hybrid progeny not correlated to electrophysiological phenotypes of their pheromone-specific antennal responses. Experientia 51:809-816.

Coyne, J. A., and ORR, H. A. 2004. Speciation. Sinauer Press.

Domingue, M. J., Starmer, W. T., and Teale, S. A. 2006. Genetic control of the enantiomeric composition of ipsdienol in the pine engraver, Ips pini. J. Chem. Ecol. 32:1005-1026.

Domingue, M. J., Musto, C. J., LinN JR., C. E., Roelofs, W. L., and BAKER, T. C. 2007. Evidence of olfactory antagonistic imposition as a facilitator of evolutionary shifts in pheromone blend usage in Ostrinia app. (Lepidoptera: Crambidae). J. Insect. Physiol. 53:488-496.

FALCONER, D. S. and MACKAY, T. F. C. 1996. An Introduction to Quantitative Genetics. Pearson, New York.

Glover, T. J., X-H, T. A. N. G., and Roelofs, W. L. 1987. Sex pheromone blend discrimination by male moths from $\mathrm{E}$ and $\mathrm{Z}$ strains of European corn borer. J. Chem. Ecol. 13:143-151.

Glover, T. J., CAmPBell, M. G., LinN JR., C. E., and Roelofs, W. L. 1991. Unique sex chromosome mediated behavioral response specificity of hybrid male European corn borer moths. Experientia 47:980-984.

HAYNES, K. F. 1997. Genetics of pheromone communication in the cabbage looper moth, Trichoplusia ni, pp. 525-534, in R. T. Cardé and A. K. Minks (eds.), Insect Pheromone Research: New Directions. Chapman and Hall, New York.

HAYNES, K. F. and HuNT 1990. A mutation in the pheromonal communication system of the cabbage looper moth, Trichoplusia ni.J. Chem. Ecol. 16:1249-1257.
Haynes, K. F., Gaston, L. K., Mistrot-Pope, M., and Baker, T. C. 1984. Potential for evolution of resistance to pheromones: Interindividual and interpopulation variation in chemical communication system of pink bollworm moth. J. Chem. Ecol. 10: $1551-1565$.

Hemmann, D. J., Allison, J. D., and Haynes, K. F. 2008. Trade-off between sensitivity and specificity in the cabbage looper moth response to sex pheromone. J. Chem. Ecol. 34:1476-1486.

Hill, W. G. and CABAllero, A. 1992. Artificial selection experiments. Annu. Rev. Ecol. Syst. 23:287-310.

Hillier, N. K. and Vickers, N. J. 2004. The role of Heliothine hairpencil compounds in female Heliothis virescens (Lepidoptera: Noctuidae) behavior and mate acceptance. Chem. Senses 29: 499-511.

Ishikawa, Y., TAKanashi, T., C-G, K. I. M., Hoshizaki, S., TATSUKI, S., and HuANG, Y. 1999. Ostrinia spp. In Japan: their host plants and sex pheromones. Entom. Exp. Appl. 91:237-244.

Kearsey, M. J. and Pooni, H. S. 1996. The Genetical Analysis of Quantitative Traits. Chapman and Hall, London.

KRASNOFF, S. B. and RoELOFS, W. L. 1990. Evolutionary trends in the male pheromone systems of arctiid moths: evidence from studies of courtship in Phragmatobia fuliginosa and Pyrrharctia isabella (Lepidoptera: Arctiidae). Zool. J. Linn. Soc. 99:319-338.

LASSANCE, J. M. 2010. Journey in the Ostrinia world: From pest to model in chemical ecology. J. Chem. Ecol. 36:1155-1169.

LASSANCE, J. M. and LÖFSTEDT, C. 2009. Concerted evolution of male and female display traits in the European corn borer, Ostrinia nubilalis. BMC Biology 7:10.

LINN JR., C. E. and RoELOFS, W. L. 1995. Pheromone communication in the moths and its role in the speciation process, pp. 263-300, in D. H. Lambert and H. Spencer (eds.), Speciation and the Recognition Concept: Theory and Application. Johns Hopkins University Press, Baltimore.

Linn JR., C. E., Young, M., Gendle, M. S., Glover, T. J., and RoELOFS, W. L. 1997. Sex pheromone blend discrimination in two races and hybrids of the European corn borer moth, Ostrinia nubilalis. Physiol. Entomol 22:212-223.

LINN, C. E. JR., O'CONNOR M., and RoELOFS, W. L. 2003. Silent genes and rare males: A fresh look at pheromone blend response specificity in the European corn borer moth, Ostrinia nubilalis. $J$. Insect Science. 3:15, Available online: insectscience.org/3.15

LinN JR., C. E., Musto, C., and Roelofs, W. L. 2007. More rare males in Ostrinia: Response of Asian corn borer moths to the sex pheromone of the European corn borer. J. Chem. Ecol. 33: $199-212$.

LÖFSTEDT, C. 1990. Population variation and genetic control of pheromone communication systems in moths. Ent. Exp. Appl. 54: 199-218.

LÖFSTEDT, C. 1993. Moth pheromone genetics and evolution. Phil. Trans. Roy. Soc. B 340:167-177.

LYNCH, M. and WALSh, B. 1998. Genetics and Analysis of Quantitative Traits. Sinauer Associates, Sunderland MA.

PAnhuis, T. M., Butlin, R., ZuK, M., and TregenZA, T. 2001. Sexual selection and speciation. Trends Ecol. Evol. 16:364-371.

PATERSON, H. E. H. 1985. The recognition concept of species. pp 2130, in E. S. Vrba, (ed.). Species and Speciation. Transvaal Museum Monograph No. 4. Pretoria.

Pélezuelo, L., Meusnier, S., Audiot, P., Bourguet, D., and PONSARD, S. 2007. Assortative mating between European corn borer pheromone races: beyond assortative meeting. PLOS ONE 2:1-10.

Phelan, P. L. 1992. Evolution of sex pheromones and the role of asymmetric tracking. pp. 265-314, in B. D. Roitberg and M. B. Isman (eds.), Insect Chemical Ecology. Chapman \& Hall, New York. 
Phelan, P. L. 1997. Genetic and phylogenetics in the evolution of sex pheromones, pp. 563-579, in R. T. Cardé and A. K. Minks (eds.), Insect Pheromone Research. Chapman and Hall, New York.

PHELAN, P. L. 1997b. Evolution of mate-signaling in moths: phylogenetic considerations and predictions from the asymmetric tracking hypothesis. pp. 240-256, in J. C. Choe, and B. J. Crespi, (eds.). The Evolution of Mating Systems in Insects and Arachnids. Cambridge University Press.

PHELAN, P. L. and BAKER, T. C. 1987. Evolution of male pheromones in moths: reproductive isolation through sexual selection. Science 235:205-207.

Roelofs, W. L., Glover, T. J., TAng, X.-H., SReng, I., Robbins, P., Eckenrode, C. J., Lofstedt, C., Hansson, B. S., and BENGTSSON, B. O. 1987. Sex pheromone production and perception in European corn borer moths requires both autosomal and sex-linked genes. Proc. Natl. Acad. Sci. USA 84:7585-7589.

Roelofs, W. L., LiU, W., HaO, G., JaIO, H., RoONEY, A. P., and LinN JR., C. E. 2002. Evolution of moth sex pheromones via ancestral genes. Proc. Natl. Acad. Sci. USA 99:13621-13626.
Roelofs, W. L. and Rooney, A. P. 2003. Molecular genetics and evolution of pheromone biosynthesis in Lepidoptera. Proc. Natl. Acad. Sci. USA 100:9179-9184.

SAKaI, R., FuKUZAWA, M., NAKANO, R., TATSUKI, S., and IshiKaWA, Y. 2009. Alternative suppression of transcription from two desaturase genes is the key for species-specific sex pheromone biosynthesis in two Ostrinia moths. Ins. Biochem. Molec. Biol. 39:62-67.

Smadja, C. and Butlin, R. K. 2009. On the scent of speciation: the chemosensory system and its role in premating isolation. Heredity 102:77-97.

SrenG, I., Glover, T., and RoElofs, W. 1989. Canalization of the redbanded leafroller moth sex pheromone blend. Arch. Insect Biochem. Physiol. 10:73-82.

SYMONDS, M. R. E. and Elgar, M. A. 2008. The evolution of pheromone diversity. Trends Ecol. Evol. 23:220-228.

Xue, B., Rooney, A. P., KaJiKawa, M., OKada, N., and Roelofs, W. L. 2007. Novel sex pheromone desaturases in the genomes of corn borers generated through gene duplication and retroposon fusion. Proc. Natl. Acad. Sci. USA 104:4467-4472. 